\title{
Trace Element Analyses by EMP: Pb-in-Monazite and New Multipoint Background Method
}

\author{
Julien Allaz ${ }^{1}$, M.J. Jercinovic ${ }^{2}$, M.L. Williams ${ }^{2}$, J.J. Donovan ${ }^{3}$ \\ 1. University of Colorado Boulder, Dept. of Geological Sciences, Boulder (CO), USA \\ 2. University of Massachusetts Amherst, Dept. of Geosciences, Amherst (MA), USA \\ ${ }^{3 .}$ University of Oregon, CAMCOR, Eugene (OR), USA
}

Precision in electron microprobe analysis is primarily a matter of counting statistics, and involves voltage, beam current, counting time, and geometric efficiency. Besides potential issues with dead-time correction and beam damage, counting statistics do not significantly affect the accuracy of major and minor element analyses. Accuracy chiefly depends on standards and matrix correction. Additional challenges with both accuracy and high precision appear when measuring trace elements [1]:

1) Analytical precision requires the use of high intensity monochromators, optimized PHA settings, high beam current, higher voltage, and/or lengthy count time. These latter requirements can lead to beam damage, surface contamination, and internal charge effects.

2) Characterization and measurement of the background become crucial for accurate results when the peak-to-background ratio approaches 1 .

3) Accurate results require correction or avoidance of peak and background interferences, even for some $2^{\text {nd }}$ or $3^{\text {rd }}$ order peaks.

Careful characterization of the analyzed material to evaluate beam exposure effects is recommended prior to analysis. In addition, it is valuable to acquire (a) qualitative WDS scans to measure background and to evaluate peak and background interferences, and (b) element mapping to characterize major element zoning.

This study focuses on accurate trace element analysis in REE-phosphate, especially $\mathrm{Pb}$-analysis for $\mathrm{U}-\mathrm{Th}-\mathrm{Pb}$ dating. Analyses were obtained on the Cameca SX Ultrachron at UMass Amherst. In addition, a new multipoint background acquisition method developed with Probe Software (J.J. Donovan) is presented which permits more accurate background acquisition - a necessity for trace element analysis.

The occurrence of REE-phosphate (monazite, xenotime) under low-grade conditions offers a rare opportunity to date a crystallization/mineralization event and possibly fluid percolation. Samples were collected in the Potsdam Formation (NY, [2]). Monazite from this low-grade metasediment (diagenesis to greenschist facies) is typically actinide-poor. Obtaining microprobe $\mathrm{U}-\mathrm{Th}-\mathrm{Pb}$ ages in young monazite $(\sim 200-500 \mathrm{Ma})$ with $1-2 \%$ Th and $<100 \mathrm{ppm} \mathrm{U}$ is challenging due to low radiogenic $\mathrm{Pb}$ production $(\sim 50-500 \mathrm{ppm})$ and a resulting high relative error on the age (5-20\%). Moreover, analysis of $\mathrm{U}$ and $\mathrm{Pb}$ is complicated by numerous peak and background interferences due to the presence of REE, Y and Th (Fig. 1). Careful background acquisition obtained on high precision WDS scans over the $\mathrm{Pb} \mathrm{Ma}, \mathrm{U} \mathrm{MB}$ and Th Ma peak regions ensures an accurate background measurement. Microprobe analysis also allows full quantification including heavy REE and other minor and trace elements, which further permits interpretation of the growth history of these crystals. For instance, this study has shown that monazite overgrowths are enriched in LREE and depleted in Y+HREE compared to detrital cores. An increase in Eu-content is probably related to the breakdown of detrital plagioclase, whereas the depletion in Y+HREE is interpreted to be compensated by the growth of authigenic xenotime. Despite the low $\mathrm{Pb}$-content, this study reveals up to five distinguishable major overgrowth events between $\sim 500 \mathrm{Ma}$ 
(time of deposition) and $\sim 200$ Ma that broadly correlate with major Paleozoic orogenic events recorded in the Appalachian Orogen to the East [2].

The new multipoint background technique has been developed to improve background correction and shorten the analysis time (compared to a high precision detailed WDS scanning; [3]). This technique is less subjective because the optimum background is calculated by the means of a consistent statistical procedure. The technique has been tested using seven different monazite reference materials, for which isotopic ages are available. Each result yields U-Th-Pb EPMA ages within the uncertainty of the isotopic age. Ti-in-quartz analysis further confirms that the multipoint background yields accurate results for trace element analysis, although other background correction methods such as the Mean Atomic Number correction [4] can yield accurate results when applied to simple matrices where a suitable blank standard can be obtained [5]. This method is combined with Time Dependent Intensity corrections to account for possible diffusion (Fig. 2).

\section{References:}

[1] MJ Jercinovic, ML Williams, J Allaz, and JJ Donovan, IOP Conference Series: Materials Science and Engineering 32 (2012), p. 1-22.

[2] J Allaz, BW Selleck, ML Williams, and MJ Jercinovic, Am. Min. 98 (2013), p. 1106-1119.

[3] J Allaz, MJ Jercinovic, ML Williams, and JJ Donovan, in preparation for Chemical Geology.

[4] JJ Donovan and T Tingle, Journal of Microscopy and Microanalysis (1996), p. 1-7.

[5] JJ Donovan and JT Armstrong, Microscopy \& Microanalysis meeting (2014) [this meeting].

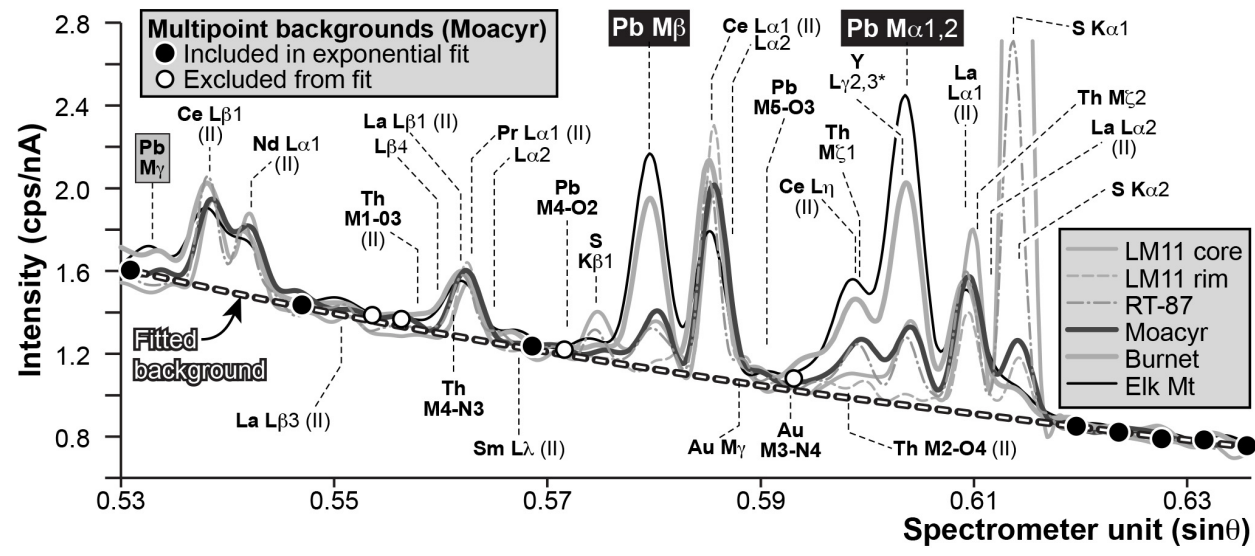

Spec 2 LPET (15 keV, 200 nA, Oum)
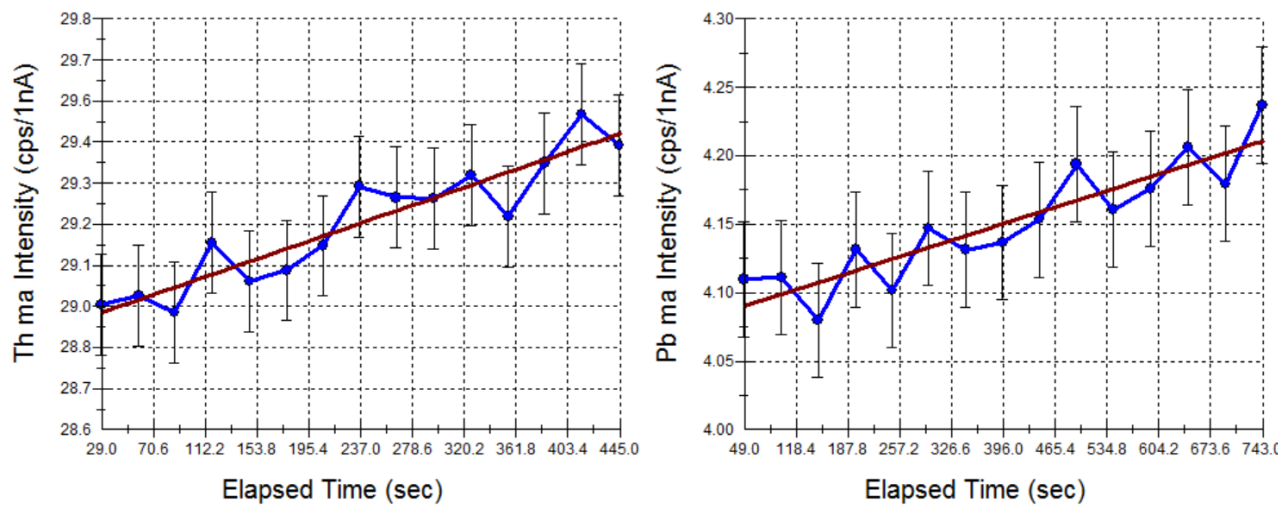

Figure 1. WDS scan smoothed using a Savitzky-Golay filter and multipoint background (dots) with exponential regression over the $\mathrm{Pb} \mathrm{Ma}$ region (very large PET crystal) for several monazite [3].
Figure 2. Time Dependent Intensity correction plot for $\mathrm{Th}$ $\mathrm{Ma}$ (left) and $\mathrm{Pb} \mathrm{Ma}$ (right) in monazite $(2 \sigma$ error bars). 